Annals of International Medical and Dental Research

E-ISSN: 2395-2822 | P-ISSN: 2395-2814

Vol-8, Issue-1 | January-February 2022

DOI: $10.53339 /$ aimdr.2022.8.1.19

Page no- 141-148 | Section- Research Article (ENT)

\title{
Our Management of Vestibular Schwannomas and Review of Literatures
}

\section{Neizekhotuo Brian Shunyu ${ }^{1 *}$, Suvamoy Chakraborty ${ }^{2}$, Zareen Lynrah ${ }^{3}$}

\author{
${ }^{1}$ Associate Professor, Department of ENT, \\ NEIGRIHMS, Shillong, Meghalaya, India. \\ Email: drnbshunyu@yahoo.com \\ Orcid ID: 0000-0003-3913-8720 \\ 2Professor, Department of ENT, NEIGRIHMS, \\ Shillong, Meghalaya, India. \\ Email: drsuvamoy@rediffmail.com \\ Orcid ID: 0000-0003-3412-5912 \\ ${ }^{3}$ Assistant Professor, Department of ENT, \\ NEIGRIHMS, Shillong, Meghalaya, India. \\ Email: zareenalynrah@gmail.com \\ Orcid ID: 0000-0002-1824-595X \\ *Corresponding author
}

Received: 06 October 2021

Revised: 25 November 2021

Accepted: 02 December 2021

Published: 22 December 2021

\begin{abstract}
There is no a clear consensus provided in the literature and there remain controversial on the treatment especially for small to medium size Vestibular schwannomas (VSs). Thus the treatment technique and approach preference vary from centre to centre. This problem too exists in our centre. The purpose of this paper is to develop a consensus in our hospital among our colleagues on the treatment of our VSs patients. We have been treating VSs patient by translabyrinthine approach from time to time for the last 5 years and found it to be a very efficient approach. This approach gives the most direct route to the tumor with excellent exposure of the internal acoustic meatus, cerebropontine angle (CPA) area without the need to retract the brain with facial nerve totally in control early in the surgery. The only problem was, when there is large posterior fossa component of the tumor present. This approach is safe with direct exposure to CPA area and have minimum intraoperative or postoperative complications.
\end{abstract}

Keywords:- Vestibular schwannomas, management, translabyrinthine approach, facial nerve.

\section{INTRODUCTION}

Vestibular schwannomas surgeries are done by neurosurgeons as well as by otorhinolaryngologists, with vigorous debate on routes of approach, intraoperative and postoperative complications, residual tumor tissue left behind after resection and tumor recurrence; and preservation of facial nerve and hearing. We have been treating our Vestibular schwannomas patients by translabyrinthine approach from time to time for the last 5 years and in this paper we try to review literatures to see the best guidelines for our Vestibular schwannomas patients. Vestibular schwannomas also known as acoustic neuromas are the most common CPA tumors $(85 \%)$ and account for $6 \%-8 \%$ of all intracranial tumors with an incidence of 0.3 to 1 per 100000 population per year. $\frac{1,2,3]}{[1}$ These tumors are called vestibular schwannomas because they develop from the Schwann cells of the vestibular root of the vestibulocochlear nerve. ${ }^{[4,5]}$ These are benign neoplasms of the nerve sheath and histologically the tumors are derived from Schwann cells of the myelin sheath without nerve fibers with smaller tumors consisting of elongated palisade cells, while large tumors have cystic degeneration in the central areas, possibly due to deficient vascularization. Symptoms are typically related to compression of adjacent cranial nerves, brain stem, or posterior fossa 
Annals of International Medical and Dental Research

E-ISSN: 2395-2822 | P-ISSN: 2395-2814

Vol-8, Issue-1 | January-February 2022

DOI: $10.53339 /$ aimdr.2022.8.1.19

Page no- 141-148 | Section- Research Article (ENT)

structures. The median age of presentation is around 50 years, unilateral in $>90 \%$ of patients, with an equal incidence on the left and right. Patients usually present with asymmetric sensorineural hearing loss and or tinnitus. True vertigo, dizziness, facial pain, numbness, and weakness are uncommon due to slow tumor growth. The etiology of Vestibular schwannomas is unknown except in inherited cases of schwannoma that present as part of the complex of neurofibromatosis type 2. More than half of all VSs grow at an average of 2-4 $\mathrm{mm} /$ year, and less than $10 \%$ regress.[6] Vestibular schwannomas may remain within the internal auditory canal or extend into the CPA and are classified into 4 grades: Grade I: exclusively intracanalicular tumor. Grade II: tumor extending into the posterior fossa, with or without an intracanalicular component, without touching the brainstem. Grade III: tumor extending into the posterior fossa, compressing the brainstem, but not shifting it from the midline Grade IV: tumor extending into the posterior fossa, compressing the brainstem, and shifting it from the midline. Progress in the diagnosis of vestibular schwannoma has played a significant role in improving treatment outcomes. The use of thin-section gadolinium-enhanced magnetic resonance imaging (MRI) as the screening method for evaluation of retrocochlear disease has allowed diagnosis of small tumors, many of which are associated with subtle, if any, symptoms. This early diagnosis not only allows patients more treatment options but also potentially improves outcome, especially in the functional preservation of facial nerves. Current treatment options include surgical resection, stereotactic radiosurgery and observation. Patients with neurofibromatosis type 2, which is characterized by bilateral Vestibular schwannomas are managed differently than those with sporadic unilateral Vestibular schwannomas.[7]

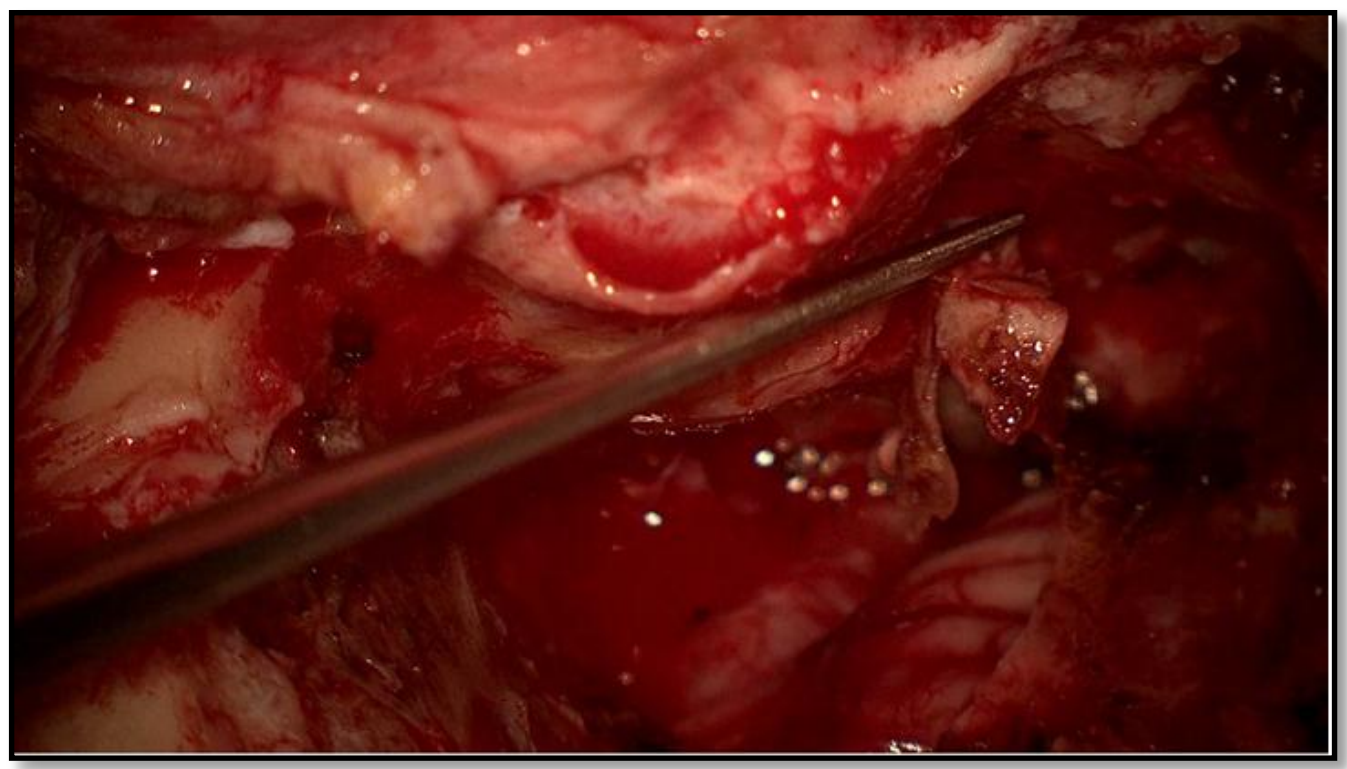

Figure 1: 
Annals of International Medical and Dental Research

E-ISSN: 2395-2822 | P-ISSN: 2395-2814

Vol-8, Issue-1 | January-February 2022

DOI: 10.53339/aimdr.2022.8.1.19

Page no- 141-148 | Section- Research Article (ENT)

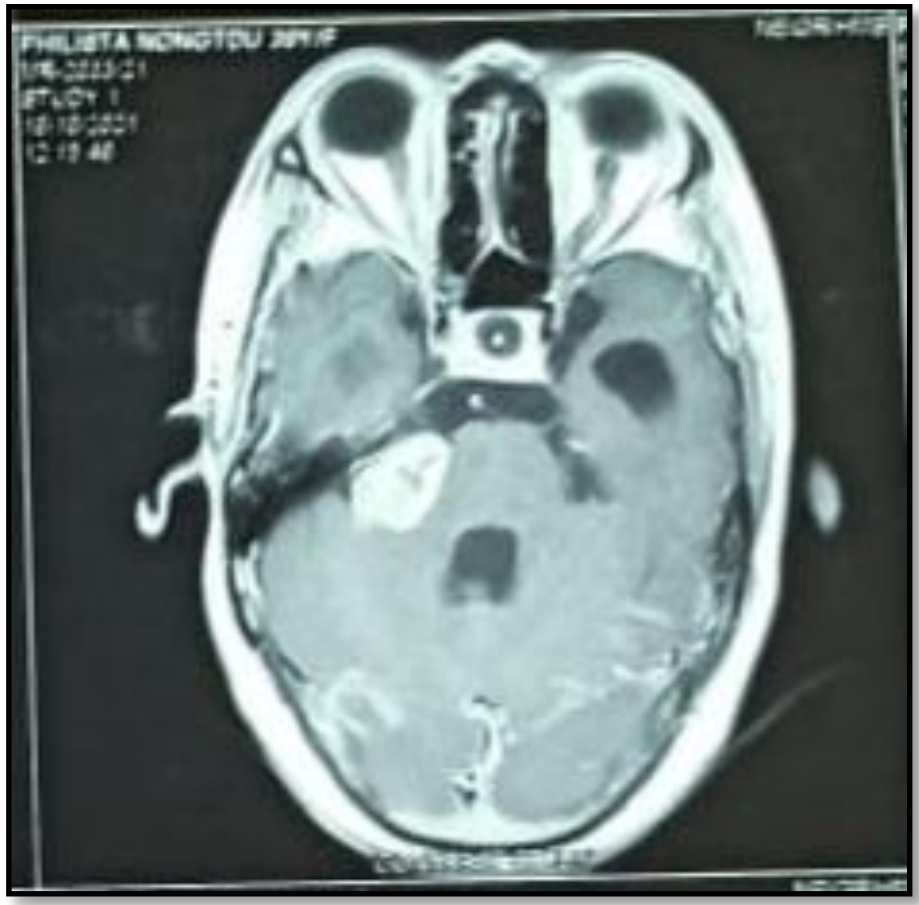

Figure 2:

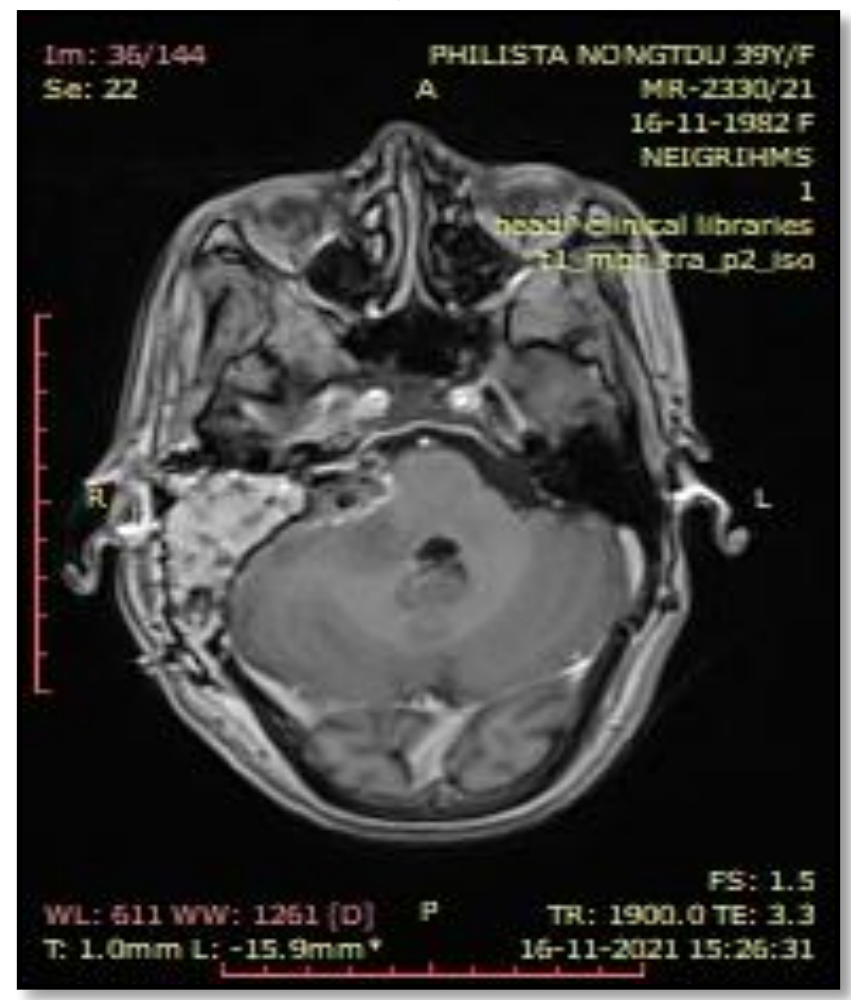

Figure 3: 


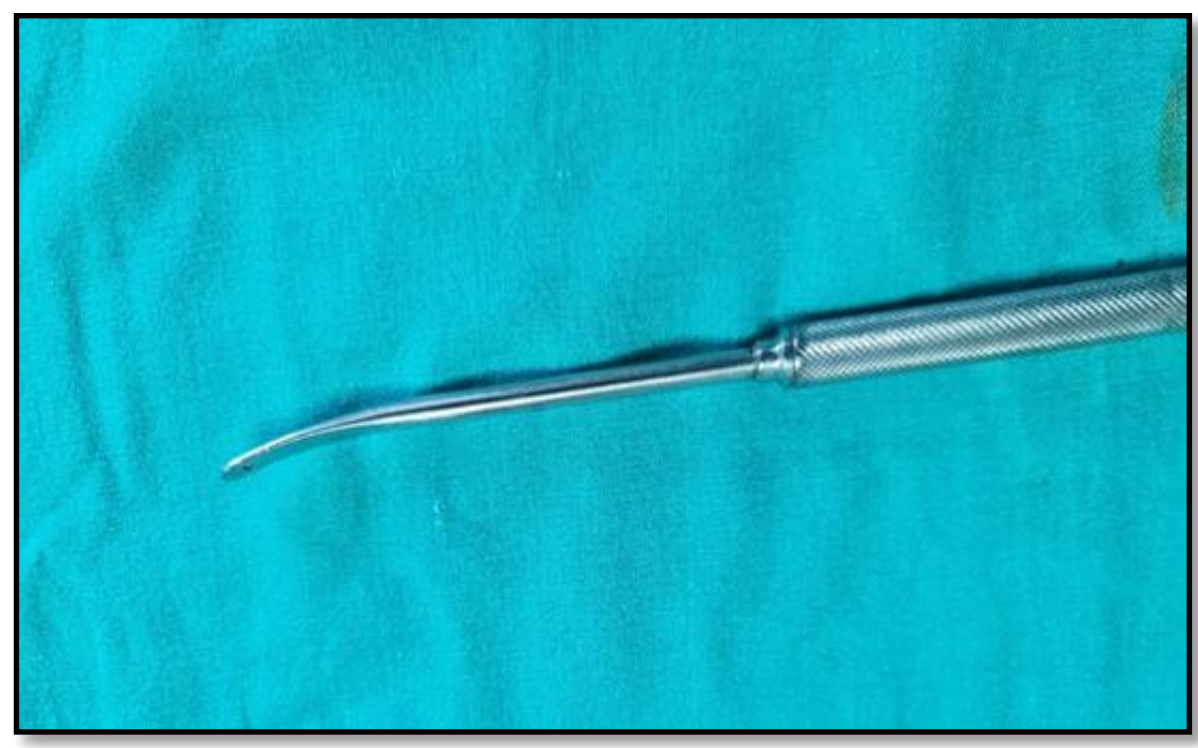

Figure 4:

\section{DISCUSSION}

In this paper we shall be discussing exclusively on sporadic unilateral Vestibular schwannomas which account for $95 \%$ of all Vestibular schwannomas. Although, for large tumors microsurgery remains the mainstay of treatment, management of the small and medium sized vestibular schwannomas has been the matter of considerable controversy. During the past century, the goal of the treatment objectives has shifted from total resection to long-term tumor control with maximum functional preservation. Kemink J L et al. [] study shows that subtotal resection of acoustic neuroma in elderly patients was not associated with clinically significant recurrence over 5 years follow up and produced highly satisfactory rates of facial preservation with low surgical morbidity. Subtotal resection of large VS with or without Stereotactic radiosurgery (SRS) post- surgery can also achieve long-term tumor control with improved cranial nerve preservation. [9,10]
Another study by Sughrue ME et al.[11] also shows that 10-year tumor control rates for gross total tumor resection and subtotal tumor resection are $78 \%$ and $82 \%$ respectively. These studies clearly suggest that there is no significant relationship between the extent of tumor resection and tumor recurrence. Thus gross total resection may be plan or done with small to medium tumor with favourable anatomy especially if the patient is young, but large tumor may be plan for subtotal resection and follow up.

As improvements in technique enabled early diagnosis, the main concern of surgeons shifted to preservation of facial nerve function and improvement in quality of facial nerve function. $[12,13,14]$ This concern is best with translabyrinthine approach as facial nerve is totally in control early in the surgery and thus can always be preserve to the maximun. Translabyrinthine approach give the most direct route to the tumor as it gives excellent exposure of the internal acoustic meatus, CPA 
Annals of International Medical and Dental Research

E-ISSN: 2395-2822 | P-ISSN: 2395-2814

Vol-8, Issue-1 | January-February 2022

DOI: 10.53339/aimdr.2022.8.1.19

Page no- 141-148 | Section- Research Article (ENT)

area/posterior fossa with minimal brain retraction as shown in [Figure 1]. Also with this approach all of the preparation for tumor removal is done extra-durally.

Another big advantage of this approach is, when the tumors have anterior inferior extension. Translabyrinthine approach give excellent direct control over the jugular bulb and thus tumor with anterior inferior extension can be remove under control with easy. [Figure 1 and Figure 2] are the pre-operative and postoperative scans of one of our patient. This tumor has anterior inferior extension, and by translabyrinthine approach we could remove the tumor as we could control over the jugular bulb which otherwise would overhang over the tumor in retrosigmoid approach. Translabyrinthine approach is safe and result in few intra-operative or post-operative complications like cerebrospinal fluid (CSF) leak and meningitis. Cerebrospinal fluid (CSF) leak with translabyrinthine approach is nearly $0 \%$ to less than $1 \% .[15,16]$ One of the disadvantage of translabyrinthine approach is when tumor have large posterior fossa component. This of course can be overcome with debulking and slow removal of the tumor; but can be very time consuming and need a lot of patience. This may be over in the future if some better suction -retractor of something like we use in our cases. [Figure 4] is a flat suction-elevator we routinely use for septum flap elevation. This suction- elevator, retracts the brain or tumor as well as sucks the blood in the field and help in developing a dissection plain. Once the subarachnoid plain of dissection is achieve, gelfoam is kept over the vital structures; and after the cottonoid is kept in the plain created, the tumor can be cauterized and debulk slowly and remove. This suction-elevator seems to be good and atraumatic unlike the normal suction which directly suck into the tumor or brain. This can be re-design and modified into a better instruction in the future. Due to the complete loss of hearing, Translabyrinthine is reserved only for patients with unserviceable hearing or poor hearing prognosis.

The retrosigmoid approach is a hearing preservation surgery but this approach has poor control over facial nerve. Preservation of facial nerve function should be a high priority in vestibular schwannoma surgery. Retrosigmoid approach compare to translabyrinthine approach had higher rate of facial nerve injury, dysphagia, and dysrhythmia.17] Delay facial paralysis is also higher in patient who underwent Tumor excision via retrosigmoid approach.[18] Retrosigmoid approach is use for resection of large extrameatal and small medial intrameatal tumors in order to preserve the hearing.[19,20,21,22] To safe the hearing, patient need to have good hearing thresholds as well as good word discrimination. Patient having good word discrimination in spite of good hearing is rare to see even in small to medium size tumor. And how good you try to save the hearing during surgery, the hearing is going to be poor if gross tumour removal is attempted.117] Unilateral hearing loss in an individual has no much consequences in turn of leading a normal life. And so if require in sporadic unilateral VSs, one side of the hearing can be sacrifice if require/needed without much consequence. Retrosigmoid approach approach to intrameatal vestibular schwannomas can be limited by a high-riding 
Annals of International Medical and Dental Research

E-ISSN: 2395-2822 | P-ISSN: 2395-2814

Vol-8, Issue-1 | January-February 2022

DOI: $10.53339 /$ aimdr.2022.8.1.19

Page no- 141-148 | Section- Research Article (ENT)

jugular bulb or obstructed by the labyrinth. [21] Cerebellum retraction may lead to parenchymal injury and early post-operative headaches following retrosigmoid approach is higher than in translabyrinthine approach. [22] Tumor infiltration of the cochlear nerve, poor pre-operative hearing, and larger tumor size decrease the likelihood of hearing preservation. [23] Not doubt the retrosigmoid approach represents a crucial surgical route to address different lesions in the cerebellopontine angle but cerebrospinal fluid (CSF) leak still remains the most frequent complication after this approach. $\underline{24,25,26,27]}$

The middle cranial fossa approach is best for small lateral internal acoustic meatus tumors, particularly those that extend to the internal acoustic meatus fundus, when hearing preservation is a treatment objective. Middle cranial fossa approach is not attempted when tumor is more than $1 \mathrm{~cm}$ due to limited exposure.[23]

Radiation in the form of Stereotactic Radiosurgery and stereotactic radiation therapy are the most commonly used techniques used to treat vestibular schwannomas. Stereotactic Radiosurgery, [28,29] is indicated in class I or II tumors. Radiation is

\section{REFERENCES}

1. Tos M, Thompsen J. Epidemiology of acoustic neuromas. J Laryngol Otol. 1984;98:685- 692.

2. Howitz MF, Johansen C, Tos M, Charabi S, Olsen $\mathrm{JH}$. Incidence of vestibular schwannoma in Denmark, 1977-1995. Am J Otol. 2000;21(5):690-4.

3. Seedat RY, Claassen AJ, Mol DA. Incidence and management of acoustic neuromas in South Africa. Otol Neurotol. 2002;23(6):996-8. doi: 10.1097/00129492-200211000-00031. aim at halting tumor growth, but with a substantial disadvantage of severely jeopardizing the surgical field if future intervention is required. Radiation can also result in high rates of early hearing loss as well as facial and trigeminal neuropathies. $[30,31,32,33]$ Radiation therapy at present time can be best reserve for large tumor who underwent subtotal resection and follow up but the tumor regrows.

Observation that is watchful waiting ("wait and scan") is offered to select patients who are typically followed with serial MR imaging every 6-12 months. Indications include patients older than 60 years of age with significant comorbidity, very small tumor size or those who are poor candidates for surgery and exhibit no major brainstem compression.

\section{CONCLUSIONS}

Translabyrinthine approach may be the prefer approach for tumor $<2.5 \mathrm{~cm}$ or tumor having significant anterior inferior extension. Tumor with large posterior fossa component, retrosigmoid may be the prefer approach. As there is no significant relationship between the extent of resection and tumor recurrence, large tumor may be managed by subtotal resection and follow up.

4. Roosli C, Linthicum FH Jr, Cureoglu S, Merchant $\mathrm{SN}$. What is the site of origin of cochleovestibular schwannomas?. Audiol Neurootol. 2012;17(2):121125. doi:10.1159/000331394

5. Zahnert T. The differential diagnosis of hearing loss. Dtsch Arztebl Int. 2011;108(25):433-444. doi:10.3238/arztebl.2011.0433

6. Al Sanosi A, Fagan PA, Biggs ND. Conservative management of acoustic neuroma. Skull Base. 2006;16(2):95-100. doi:10.1055/s-2006-934112 
Annals of International Medical and Dental Research

E-ISSN: 2395-2822 | P-ISSN: 2395-2814

Vol-8, Issue-1 | January-February 2022

DOI: 10.53339/aimdr.2022.8.1.19

Page no- 141-148 | Section- Research Article (ENT)

7. Slattery WH. Neurofibromatosis type 2. Otolaryngol Clin North Am. 2015;48(3):443-60. doi: 10.1016/j.otc.2015.02.005.

8. Kemink JL, Langman AW, Niparko JK, et al. Operative management of acoustic neuromas: the priority of neurologic function over complete resection. Otolaryngol Head Neck Surg. 1991;104:96-99.

\section{https://doi.org/10.1177\%2F019459989110400117}

9. Huang MJ, Kano H, Mousavi SH, Niranjan A, Monaco EA 3rd, Arai Y, et al. Stereotactic radiosurgery for recurrent vestibular schwannoma after previous resection. J Neurosurg. 2017;126(5):1506-1513. doi: 10.3171/2016.5.JNS1645.

10. Carlson ML, Tveiten OV, Driscoll CL, Goplen FK, Neff BA, Pollock BE, et al. Long-term quality of life in patients with vestibular schwannoma: an international multicenter cross-sectional study comparing microsurgery, stereotactic radiosurgery, observation, and nontumor controls. J Neurosurg. 2015;122(4):833-42. doi: 10.3171/2014.11.JNS14594.

11. Sughrue ME, Kaur R, Rutkowski MJ, Kane AJ, Kaur G, Yang I, et al. Extent of resection and the longterm durability of vestibular schwannoma surgery. J Neurosurg. 2011;114(5):1218-23. doi: 10.3171/2010.11.JNS10257.

12. Hitselberger WE, Pulec JL. Trigeminal nerve (posterior root) retrolabyrinthine selective section. Operative procedure for intractable pain. Arch Otolaryngol. 1972;96(5):412-5. doi: 10.1001/archotol.1972.00770090644004.

13. House JW, Brackmann DE. Facial nerve grading system. Otolaryngol Head Neck Surg. 1985;93(2):146-7. doi: 10.1177/019459988509300202.

14. Yaşargil MG. A legacy of microneurosurgery: memoirs, lessons, and axioms. Neurosurgery. 1999;45(5):1025-92. doi: 10.1097/00006123199911000-00014.

15. Lipschitz N, Kohlberg GD, Tawfik KO, et al. Cerebrospinal Fluid Leak Rate after Vestibular Schwannoma Surgery via Middle Cranial Fossa Approach. J Neurol Surg B Skull Base. 2019;80(4):437-440. doi:10.1055/s-0038-1675752

16. Merkus $P$, Taibah A, Sequino G, Sanna M. Less than $1 \%$ cerebrospinal fluid leakage in 1,803 translabyrinthine vestibular schwannoma surgery cases. Otol Neurotol. 2010;31(2):276-83. doi: 10.1097/MAO.0b013e3181cc06ad.
17. Cole T, Veeravagu A, Zhang M, et al. Retrosigmoid Versus Translabyrinthine Approach for Acoustic Neuroma Resection: An Assessment of Complications and Payments in a Longitudinal Administrative Database. Cureus. 2015;7(10):e369. doi:10.7759/cureus.369

18. Carlstrom LP, Copeland WR 3rd, Neff BA, Castner ML, Driscoll CL, Link MJ. Incidence and Risk Factors of Delayed Facial Palsy After Vestibular Schwannoma Resection. Neurosurgery. 2016;78(2):251-5. doi: 10.1227/NEU.0000000000001015.

19. Samii M, Matthies C. Management of 1000 vestibular schwannomas (acoustic neuromas): hearing function in 1000 tumor resections. Neurosurgery. 1997;40(2):248-60;260-2. doi: 10.1097/00006123-199702000-00005.

20. Samii M, Gerganov V, Samii A. Improved preservation of hearing and facial nerve function in vestibular schwannoma surgery via the retrosigmoid approach in a series of 200 patients. J Neurosurg. $\quad 2006 ; 105(4): 527-35 . \quad$ doi: 10.3171/jns.2006.105.4.527.

21. Blevins NH, Jackler RK. Exposure of the lateral extremity of the internal auditory canal through the retrosigmoid approach: a radioanatomic study. Otolaryngol Head Neck Surg. 1994;111(1):81-90. doi: 10.1177/019459989411100116.

22. Ruckenstein MJ, Harris JP, Cueva RA, Prioleau G, Alksne J. Pain subsequent to resection of acoustic neuromas via suboccipital and translabyrinthine approaches. Am J Otol. 1996;17(4):620-4.

23. Wanibuchi $M$, Fukushima $T$, McElveen JT Jr, Friedman AH. Hearing preservation in surgery for large vestibular schwannomas. J Neurosurg. 2009;111(4):845-54. doi: 10.3171/2008.12.JNS08620.

24. Montano N, Signorelli F, Giordano M, et al. Factors associated with cerebrospinal fluid leak after a retrosigmoid approach for cerebellopontine angle surgery. Surg Neurol Int. 2021;12:258. doi:10.25259/SNI_42_2021

25. Cueva RA, Mastrodimos B. Approach design and closure techniques to minimize cerebrospinal fluid leak after cerebellopontine angle tumor surgery. Otol Neurotol. 2005;26(6):1176-81. doi: 10.1097/01.mao.0000176174.94764.3b. 
Annals of International Medical and Dental Research

E-ISSN: 2395-2822 | P-ISSN: 2395-2814

Vol-8, Issue-1 | January-February 2022

DOI: $10.53339 /$ aimdr.2022.8.1.19

Page no- 141-148 | Section- Research Article (ENT)

26. Dandy WE. Removal of cerebellopontine (acoustic) tumors through a unilateral approach. Arch Surg. 1934;29:337-44.

27. Ling PY, Mendelson ZS, Reddy RK, Jyung RW, Liu JK. Reconstruction after retrosigmoid approaches using autologous at graft-assisted Medpor Titan cranioplasty: Assessment of postoperative cerebrospinal fluid leaks and headaches in 60 cases. Acta Neurochir (Wien). 2014;156:1879-88.

28. House WF. Transtemporal bone microsurgical removal of acoustic neuromas: evolution of transtemporal bone removal of acoustic tumors. Arch Otolaryngol. 1964;80:731-42.

29. Delgado TE, Bucheit WA, Rosenholtz HR, Chrissian S. Intraoperative monitoring of facila muscle evoked responses obtained by intracranial stimulation of the facila nerve: a more accurate technique for facila nerve dissection. Neurosurgery. 1979;4(5):418-21. doi: 10.1227/00006123-19790500000007.

30. Kondziolka D, Lunsford LD, McLaughlin MR, Flickinger JC. Long-term outcomes after radiosurgery for acoustic neuromas. $\mathrm{N}$ Engl J Med.
1998;339(20):1426-33.

doi: 10.1056/NEJM199811123392003.

31. Flickinger JC, Lunsford LD, Linskey ME, Duma $\mathrm{CM}$, Kondziolka D. Gamma knife radiosurgery for acoustic tumors: multivariate analysis of four year results. Radiother Oncol. 1993;27(2):91-8. doi: 10.1016/0167-8140(93)90127-t.

32. Foote RL, Coffey RJ, Swanson JW, Harner SG, Beatty CW, Kline RW, et al. Stereotactic radiosurgery using the gamma knife for acoustic neuromas. Int J Radiat Oncol Biol Phys. 1995;32(4):1153-60. doi: 10.1016/03603016(94)00454-s.

33. Jacob JT, Pollock BE, Carlson ML, Driscoll CL, Link MJ. Stereotactic radiosurgery in the management of vestibular schwannoma and glomus jugulare: indications, techniques, and results. Otolaryngol Clin North Am. 2015;48(3):515-26. doi: 10.1016/j.otc.2015.02.010.

Source of Support: Nil, Conflict of Interest: None declared 